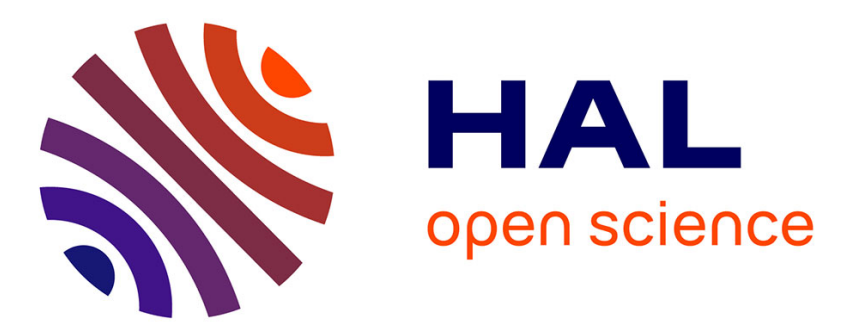

\title{
The Main Problems in the Design and Management of MOOCs
}

\author{
Luis Mendes Bezerra, Márcia Da Silva
}

\section{To cite this version:}

Luis Mendes Bezerra, Márcia Da Silva. The Main Problems in the Design and Management of MOOCs. IFIP International Conference on Advances in Production Management Systems (APMS), Sep 2015, Tokyo, Japan. pp.500-506, 10.1007/978-3-319-22756-6_61 . hal-01417599

\author{
HAL Id: hal-01417599 \\ https://hal.science/hal-01417599
}

Submitted on 15 Dec 2016

HAL is a multi-disciplinary open access archive for the deposit and dissemination of scientific research documents, whether they are published or not. The documents may come from teaching and research institutions in France or abroad, or from public or private research centers.
L'archive ouverte pluridisciplinaire HAL, est destinée au dépôt et à la diffusion de documents scientifiques de niveau recherche, publiés ou non, émanant des établissements d'enseignement et de recherche français ou étrangers, des laboratoires publics ou privés. 


\title{
The Main Problems in the Design and Management of MOOCs
}

\author{
Luis Naito Mendes Bezerra, Márcia Terra da Silva \\ Paulista University-UNIP, Graduate Program in Production Engineering, Dr. Bacelar St. 1212, \\ São Paulo, Brazil \\ luisnaito@yahoo.com.br \\ marcia.terra@uol.com.br
}

\begin{abstract}
Despite the global scale, the wide range of courses and the high number of enrollments, some challenges have been emerging for the universe of the MOOCs (Massive Open Online Courses), especially those related to project and management aspects. This article aims to identify the main problems faced by the managers of the MOOCs. Hence, an exploratory study was carried out through the analysis of existing publications in academic databases. The results show that after the survey it was possible to identify and analyze six problems, the main one of which was the very low completion rate of this type of course.
\end{abstract}

Keywords: MOOCs, problems of MOOCs, challenges of MOOCs.

\section{$1 \quad$ Introduction}

Recently there emerged a new modality of distance education, known as MOOC (Massive Open Online Course). The MOOCs are open courses, with fully online format, without preconditions, without initial billing rates and with the potential to distribute education on a global scale, including to enable students from developing countries have access to institutions and courses of quality at low cost [1-3].

In 2011, about 3 years after the first MOOC $^{1}$ had been offered, Sebastian Thrun created the Artificial Intelligence course at Stanford University that attracted more than 160,000 students from 190 countries. As from 2011, the growth of this distance education modality has been breathtaking, with the initial emergence of three big hubs - Coursera, Udacity and EdX - for the provision of MOOCS [4-6].

The research shows that the main reasons for the interest of students in MOOCs can be summarized in four relevant aspects: interest in learning about certain subjects; knowledge increase; updating on some previously seen subject or learning something specific that should contribute to the professional development [7, 8].

However, despite the global scale having been reached, the large number of students served and the considerable growth in the number of courses, some challenges have been appeared in the universe of the MOOCs. Several authors have researched

1 The first MOOC was created in September 2008 in Canada. 
problematic aspects in the design and management of these courses, such as, for example, the pedagogical model $[9,10]$ and the quality of MOOCs [11].

Through this paper, based on a bibliographical study, the main problems in the design and management of MOOCs can therefore be objectively identified and analyzed beyond pointing out the most significant problem and clarifying how the issues relate to each other.

In addition to this introduction, this paper is divided into six parts. In the initial section, the methodology used to achieve the objective of this research is presented, then a study on the main problems in the design and management of MOOCs. Afterwards, the results and analysis are shown, followed by conclusions and, eventually, the bibliographical references.

\section{$2 \quad$ Methodology}

From an exploratory, non-systematic study, conducted through the analysis of existing publications in academic databases, such as Springer, Science Direct, ERIC database, ACM Digital Library and Google Scholar, the main problems in the design and management of MOOCs were identified.

The bibliographic survey covers the period between the offer of the first MOOC in 2008 [12] and the year in which the research has been conducted (2015). After reading and analyzing titles and abstracts, 20 articles that constitute this analysis were selected.

\section{Main Problems in the Design and Management of MOOCs}

The MOOCs, as already said, have a huge potential to provide free education on a global scale, with the opportunity of democratizing access to higher education of good quality [2]. No doubt his growth has been quite expressive. Only in Europe, according to the website of [13], which gathers data about the MOOCs in European countries, 510 courses were offered in April 2014. In the same year, in September, there were 770 courses, a growth of $50.98 \%[13]$.

Despite the apparent expansion, the MOOCs model is the target of a lot of criticism and concerns because, besides being a still recent teaching mode, it is often compared, erroneously, to traditional distance education courses and also seen as competitor of face-to-face teaching. Such concerns, however, can be considered unfounded since they are modalities with differentiated goals and functions.

The MOOCs, due to their open character and short duration, do not allow for the issue of undergraduate or graduate certificates and furthermore carry out a complementary role to distance education and face-to-face teaching, providing students the opportunity to expand their knowledge and/or have a professional update. Another important point that distinguishes them from distance education and private face-toface teaching is the fact that the services offered by MOOCs are free of fees because 
their business model is different from traditional education institutions [3] as will be discussed below.

The following is an attempt to interrelate the main problems encountered in literature regarding the design and management of these courses.

- Business model - some authors cite the MOOCs as a new business model for higher education institutions. Even though the courses are exempt from fees for registration and access to content, institutions may charge fees for issuing certificates. According to the author [12], the business model of the MOOCs is related to the one adopted by technology companies, such as Google and RedHat Linux, which provide a basic service to customers, then offer add-ons to be paid for. In the case of MOOCs, the charge for the certificate would be the complementary service. Considering the large number of students, such an initiative could generate a sustainable business model $[1,12]$. However, at this point, such a model is accessible only for a small portion of educational institutions, such as Harvard, Stanford and MIT, which are using their long tradition and excellent academic reputation to receive sufficient funds to pay for the costs of creating platforms for content production and distribution on a large scale, resulting in the creation of for-profit companies and inspired by the model of Silicon Valley startups such as Coursera (Stanford University) and Edx (MIT and Harvard) [6]. The MOOCs can also serve as a marketing element to the major institutions of higher education, mainly for institutions of great reputation and prestige like the previously already mentioned ones. According to the author [6], about $65 \%$ of all students who enrolled on the Coursera platform reside outside of the United States, a fact that could help to attract more foreign students who would pay substantial registration fees for attending face-to-face undergraduate and graduate courses.

- Very low completion rate of the courses - a concern often raised in the surveys conducted on the MOOCs relates to the fact that thousands of students enroll but only a small part of them have completed the courses. Abandonment in this teaching modality is generally quite high, currently around $90 \%$ [6, 14-18]. According to the author [19], the completion rate is related to the number of people who receive the certificate or are approved to the course. According to the author [20], the completion rate of MOOCs cannot be compared to that of face-to-face courses or even traditional distance education because MOOCs students do not pay tuition and also do not receive university credits; hence the motivation for its completion is largely inherent in the model of the course itself.

- Certification - the majority of MOOCs are adaptations of subjects offered in the degrees of higher education institutions around the world. Thus, they do not configure a full degree course and their certification could generate some questions, such as if being free of cost, they would have the same value as a paid face-to-face course. Moreover, it would be important to analyze how potential employers assess such certificates $[1,2]$. 
- Pedagogical model - the most accepted classification for the approach or pedagogical model is the one that divides the MOOCs into two categories: cMOOCs and xMOOCs, according to authors like [6, 9, 21-23]. In this context, the cMOOCs constitute the first generation - beginning in 2008 - with a focus on creating and generating knowledge through interaction among the participants. In this model, the participants are encouraged to use a variety of technologies and to reflect on their learning, following the principles of connectivism which considers the intense interaction between the participants as fundamental for the construction of knowledge. The xMOOCs are the second generation - beginning in 2012 - with pedagogical approach based on behaviorism and more traditional format. Counting on content and assessments based on previously provided teaching materials. In this model, monitoring and mentoring actions are less systematic, with discussion forum and automated assessment. This is the model that prevails today, being adopted by the major platforms Coursera and edX [24-26].

- Quality - According to the author [27], the concern with quality in the MOOCs is related to the problem of high drop-out rates in this type of course. Still according to the same authors, how can MOOCs managers declare quality learning in their courses, if students are failing to complete the same? Again according to the author [27], the MOOCs should follow the same quality principles applied in traditional courses because, to a great extent, they derive from undergraduate disciplines, being produced by the same faculty, with the same material, however, adapted to the new environment. Therefore, it is important to be concerned with the issues involving the guarantee (quality assurance) and improvement (quality enhancement) of the quality of MOOCs. The quality assurance process is mentioned in the works of [11], dealing with a quality program called UNED MOOC and also by [27], dealing with the model named OpenupEd Quality Label.

- Validation and plagiarism - according to the author [2], a fundamental aspect and a great challenge for the MOOCs is to ensure that the works are original and valid. To do so, a system to prevent and detect plagiarism of the activities generated by the students is necessary. Still according to the same authors, the platform Coursera studies to deploy a software for detecting plagiarism, just as Udacity and Edx which formed a partnership with Pearson VUE, a test center provider, to validate the tests in supervised form. However, it is important to highlight that this practice entails generating cost to students. 
Table 1 summarizes the six problems and the author(s) that were used as a reference.

Table 1. summary of problems and authors

\begin{tabular}{lll}
\hline$\#$ & Problem & Author(s) \\
\hline 1 & Business model & $1 ; 12 ; 6$ \\
2 & Very low completion rate of the courses & $14 ; 15 ; 6 ; 16 ; 17 ; 18 ; 19 ; 20$ \\
3 & Certification & $1 ; 2$ \\
4 & Pedagogical model & $6 ; 21 ; 22 ; 23 ; 9 ; 24 ; 25 ; 26$ \\
5 & Quality & $27 ; 11$ \\
6 & Validation and plagiarism & 2 \\
\hline
\end{tabular}

\section{$4 \quad$ Results and Discussion}

This section is dedicated to the presentation of the relations between the previously presented differing concepts.

The business model currently adopted by the big hubs in the offer of MOOCs, as Coursera, Udacity and Edx, considers that such courses aim to reach a large number of students, attracted by the opportunity to participate in courses offered by major institutions of higher education like Harvard, MIT and Stanford [18].

Although there are no registration fees or tuition, educational institutions may have a new source of financial resources through charging for issuing certificates. For example, the University of Washington, which is part of the Coursera platform, is testing a hybrid model, which introduces more rigor in granting academic credits and also considers charging a fee for the issuance of the certificate [12]. However, the sustainability of such a model can be compromised if the courses have a high drop-out rate, around $90 \%$ [19]. Hence, increasing the retention of students would be a measure of paramount importance to ensure the sustainability of the currently practiced business model.

The work of [20] suggests some measures to increase the retention rate such as attending the students according to the pace and profile of each individual, teachers who motivate the student to complete the course, with the use of techniques such as the recognition of the results achieved by the students, beyond increasing the participation and interaction between students and teachers in the discussion forums for each course. Additionally, thinking of increasing retention, the MOOC managers should also be concerned with issues involving quality guarantee (quality assurance) and improvement of quality (quality enhancement) of the MOOCs.

The issuance, validity, form and the market acceptance of the certificates issued by institutions that offer MOOCs is another aspect that has caused concern and discussion among those involved in the MOOC segment. To the extent that such certificates are accepted by employers and educational institutions, it is likely that this fact affects 
the way the MOOCs are seen in relation to traditional teaching. Further discussion can be found in the works of authors $[28,29,30]$.

Of all the problems pointed out in the survey, the main challenge and key problem for the MOOC managers is related to the very low completion rate of this type of course. Such a problem is caused by the quality of the courses and also by the adopted pedagogical model. It is necessary to also consider that the higher the completion rate of a particular course is, the more students could potentially pay for the certificates of completion issuance, contributing to the business model being sustainable.

\section{Conclusions}

The research aimed at identifying and analyzing the main problems in the design and management of MOOCs, based on a bibliographical study. After the research it was possible to identify six relevant issues, such as the very low completion rate, the certification of the courses, the pedagogical model, the process involving the assurance and improvement of the MOOC quality, the acceptance of the certificates, in addition to the concern with validation and plagiarism in this type of course.

The analysis showed that the main challenge for MOOC managers is to increase the retention rate of their courses. From the management point of view, the reduction of the drop-out rate, nowadays around $90 \%$, would make it possible that the business model becomes more feasible once it would allow that more students could complete the courses and, therefore, consider the payment of fees for the certificate issuance. Furthermore is important that employers know the MOOCs better and increasingly accept such certificates in the same way that face-to-face course certificates are accepted.

The concern with quality is another aspect to be considered by the managers because the adoption of quality assurance and improvement programs would be timely to meet the expectations of students and increase the retention rates of the courses.

In a general analysis, for consolidating the business model of the MOOCs, the issues involving the pedagogical model, the increase of the completion rate and the acceptance of the certificates need to be thoroughly questioned and analyzed in order to achieve a level of maturity which is sufficient to ensure sustainability and continuity of this education modality.

The main contribution of this research was to interrelate the main problems in the design and management of MOOCs as to then identify the most significant problem, in this case the very low completion rate, beyond examining how the issues interrelate.

In terms of future work, a deeper study about the main reasons for the high dropout rates in MOOCs is suggested. 


\section{References}

1. Hyman, P.: In the year of disruptive education. Communications of ACM. 55, 20-22 (2012).

2. Cooper, S., Sahami, M.: Reflections on Stanford's Moocs. Communications of. ACM. 56, 28 30 (2013).

3. Ong, B.S., Grigoryan, A.: MOOCs and Universities: Competitors or Partners? 5, 373-376 (2014).

4. Little, G.: Massively Open? J. Acad. Librariansh. 308-309 (2013).

5. Mallon, M.: MOOCs. Public Service Quartely. 9, 46-53 (2013).

6. Sandeen, C.: Integrating MOOCS into traditional higher education: the emerging "MOOC 3.0" Era. Change Mag. High. Learn. 45, 34-39 (2013).

7. Fini, A.: The technological dimension of a massive open online course: The case of the CCK08 course tools. Int. Rev. Res. Open Distrib. Learn. 10, (2009).

8. Belanger, Y., Thornton, J.: Bioelectricity: A quantitative approach Duke University's first MOOC. (2013).

9. Vardi, M.Y.: Will MOOCs destroy academia? Communications of ACM. 55, 5 (2012).

10. Fournier, H., Kop, R., Durand, G.: Challenges to research in MOOCs. J. Online Learn. Teach. 10, (2014).

11. Read, T., Rodrigo, C.: Toward a quality model for UNED MOOCs. ELearning Pap. http://www.openeducationeuropa.eu/en/article/Toward-a-Quality-Model-for-UNED-MOOCs. (2014).

12. Dellarocas, C., Van Alstyne, M.: Money models for MOOCs. Communications of ACM. 56, 25-28 (2013).

13. Open Education Europa (2014). Avalible at: http://openeducationeuropa.eu/en/european_scoreboard moocs.

14. Daniel, J.: Making sense of MOOCs: Musings in a maze of myth, paradox and possibility. J. Interact. Media Educ. 2012, 1-20 (2012).

15. Morris, L.V.: MOOCs, emerging technologies, and quality. Innov. High. Educ. 38, 251-252 (2013).

16. Hew, K.F., Cheung, W.S.: Students' and instructors' use of massive open online courses (MOOCs): Motivations and challenges. Educ. Res. Rev. 12, 45-58 (2014).

17. Wilkowski, J., Deutsch, A., Russell, D.M.: Student skill and goal achievement in the mapping with Google MOOC. Proceedings of the first ACM conference on Learning@ scale conference. pp. 3-10. ACM (2014).

18. Alraimi, K.M., Zo, H., Ciganek, A.P.: Understanding the MOOCs continuance: The role of openness and reputation. Computers \& Education. 80, 28-38 (2015).

19. Jordan, K.: Initial trends in enrolment and completion of massive open online courses. International. Review of. Research in Open and Distributed Learn. 15, (2014).

20. Khalil, H., Ebner, M.: MOOCs completion rates and possible methods to improve retention-A literature review. World Conference on Educational Multimedia, Hypermedia and Telecommunications. pp. 1305-1313 (2014).

21. Welsh, D.H., Dragusin, M.: The New Generation of Massive Open Online Course (MOOCS) and Entrepreneurship Education. Small Bus. Institute ${ }^{\circledR}$ J. 9, 51-65 (2013).

22. Zutshi, S., O'Hare, S., Rodafinos, A.: Experiences in MOOCs: The perspective of students. Am. J. Distance Educ. 27, 218-227 (2013).

23. Saadatmand, M., Kumpulainen, K.: Participants' perceptions of learning and networking in connectivist MOOCs. MERLOT J. Online Learn. Teach. 10, 16-30 (2014).

24. Blanco, Á.F., García-Peñalvo, F.J., Sein-Echaluce, M.: A methodology proposal for developing adaptive cMOOC. Proceedings of the First International Conference on Technological Ecosystem for Enhancing Multiculturality. pp. 553-558. ACM (2013).

25. Clow, D.: MOOCs and the funnel of participation. Proceedings of the Third International Conference on Learning Analytics and Knowledge. pp. 185-189. ACM (2013). 
$8 \quad$ L. N. M. Bezerra and M. T. da Silva

26. Kennedy, J.: Characteristics of Massive Open Online Courses (MOOCs): A Research Review, 2009-2012. J. Interact. Online Learn. 13, (2014).

27. Rosewell, J., Jansen, D.: The OpenupEd quality label: benchmarks for MOOCs. INNOQUAL International Journal for Innovation and Quality in Learning. 2, 88-100 (2014).

28. Li, X., Chang, K., Yuan, Y.: Massive Open Online Proctor: Protecting the Credibility of MOOCs Certificates. Proceedings of the CSCW - Collaboration in the Open Classroom. Pp. 1129-1137. ACM (2015).

29. Schroeder, R.: Emerging Open Online Distance Education Environment. Continuing Higher Education Review. 76, 90-99 (2012).

30. Venkatesh, N.: Analysis on Massive Open Online Courses (MOOC): Oportunities and Challenges towards $21^{\text {st }}$ Century Online Education.3, 203-220 (2014). 